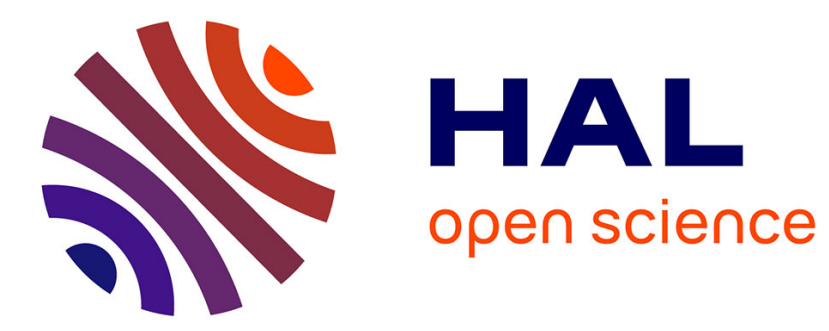

\title{
Numerical study of non-Boussinesq convection in a ventilated cavity
}

Oussama Chabani, Stéphane Abide, Nacer Lamrous, Belkacem Zeghmati

\section{To cite this version:}

Oussama Chabani, Stéphane Abide, Nacer Lamrous, Belkacem Zeghmati. Numerical study of nonBoussinesq convection in a ventilated cavity. Computational Thermal Sciences: An International Journal, 2017, 9 (2), pp.135-149. 10.1615/ComputThermalScien.2017018912 . hal-01589285

\section{HAL Id: hal-01589285 \\ https://hal.science/hal-01589285}

Submitted on 30 Oct 2018

HAL is a multi-disciplinary open access archive for the deposit and dissemination of scientific research documents, whether they are published or not. The documents may come from teaching and research institutions in France or abroad, or from public or private research centers.
L'archive ouverte pluridisciplinaire HAL, est destinée au dépôt et à la diffusion de documents scientifiques de niveau recherche, publiés ou non, émanant des établissements d'enseignement et de recherche français ou étrangers, des laboratoires publics ou privés. 


\title{
NUMERICAL STUDY OF NON-BOUSSINESQ CONVECTION IN A VENTILATED CAVITY
}

\author{
O. Chabani, ${ }^{1}$ S. Abide, ${ }^{2, *}$ N. Lamrous, ${ }^{1} \&$ B. Zeghmati ${ }^{2}$ \\ ${ }^{1}$ Laboratoire de Mécanique, Structure et Energétique, Université Mouloud MAMMERI de \\ Tizi-Ouzou, Tizi-Ouzou, Algérie \\ ${ }^{2}$ Laboratoire de Mathématiques et de Physique, Université de Perpignan Via Domitia, \\ Perpignan, France
}

\begin{abstract}
The non-Boussinesq convection in a ventilated square cavity is studied numerically. The flow is driven by a prescribed constant inlet velocity at the top-left wall and an outlet located at the bottom-right wall. The prescribed temperature difference, between the inlet flow and the walls of the cavity, involves buoyancy forces which modify the flow. The density variations are considered by means of a low-Mach-number formulation, which is discretized by a projection scheme based on a second-order finitedifference discretization. The steady solutions associated to forced and mixed convection are presented. A discussion based on the flow and heat transfer features is proposed. Especially, the deviation from the Boussinesq model is highlighted in the case of mixed convection.
\end{abstract}

KEY WORDS: ventilated cavity, low Mach number, numerical simulation, heat transfer

\section{INTRODUCTION}

Convection heat transfer is dominant in several thermal engineering applications. Some examples include the cooling of electronic devices and the design of greenhouses. Thus, in the last 40 years, a large number of numerical studies have been reported in the literature to describe heat transfer coefficient exchange, particularly, for flows in wall bounded domain, and precisely, flows in confined domain with several inlet/outlet ports such as ventilated cavity.

A ventilated cavity refers to flows in a rectangular or parallelepipedic domain having one or more inlet/outlet ports. On the application sides, building ventilation motivates an important amount of experimental and numerical studies. For instance, Nielsen et al. (1978) have investigated the turbulent flow in a parallelepipedic domain with an inlet on the upper-left face and with an outlet port on the bottom-right face. This flow configuration has been considered for experiments (Nielsen et al., 1978), large Eddy simulations (Zhang and Chen, 2000), or RANS computation (Limane et al., 2015). A flow in a cubical cavity has also been considered in the recent work of van Hooff et al. (2014) or previously by Ezzouhri et al. (2009). These works highlight the specific features, such as transitional flows, turbulence anisotropy, and adverse pressure gradient (van Hooff et al., 2014). Heat transfer also contributes to modify the flow structure. For instance, Ezzouhri et al. (2009) have outlined the existence of two mean flows for an identical flow configuration.

Laminar flows in rectangular domain are also of primary interest in the understanding of heat transfer mechanisms. Applications are encountered in electronic device cooling. Heat transfers in a cavity can be controlled by introducing one or several inlet velocities; this is the consequence of the forced convection mechanism. Saeidi and Khodadadi (2006) well illustrated this kind of investigation. They have proposed a parametric study to show the influence of the inlet and outlet locations on the flow features and heat transfers. Their results suggest that the Nusselt number achieves the highest values for an outlet at the vicinity of the corner. The lowest one is achieved for an outlet 


\section{NOMENCLATURE}

\section{Roman Symbols}

$C p \quad$ heat capacity, $\mathrm{J} / \mathrm{kg} \mathrm{K}$

Gr $\quad$ Grashof number, $H^{3} \in g / v^{2}$

$H \quad$ cavity height, $\mathrm{m}$

$h$ opening height, $\mathrm{m}$

$\mathrm{Nu}$ Nusselt number

$\mathrm{P}_{t h}$ thermodynamic pressure, $\mathrm{Pa}$

$p \quad$ dynamic pressure, $\mathrm{Pa}$

Pr Prandtl number, $v / \alpha$

Ri Richardson number, $\mathrm{Gr} / \mathrm{Re}^{2}$

Re Reynolds number, $u_{i} H / v$

$T$ temperature, $\mathrm{K}$

u dimensionless velocity vector

\section{Greek Symbols}

$\alpha$ thermal diffusivity

$\epsilon$ non Bousinesq parameter, $\Delta T / T_{c}$

$\gamma$ Laplace coefficient (heat capacity fraction)

$v$ kinematic viscosity, $\mathrm{m}^{2} / \mathrm{s}$

$\rho$ density, $\mathrm{kg} / \mathrm{m}^{3}$

$\tau$ dimensionless stress vector

$\theta$ dimensionless temperature

\begin{tabular}{ll}
\multicolumn{2}{l}{ Subscripts } \\
$c$ & cold \\
$i$ & inlet \\
$h$ & hot
\end{tabular}

port located at the middle of the cavity walls (Saeidi and Khodadadi, 2006). Saeidi and Khodadadi (2007) considered a time-dependent sinusoidal inlet velocity and shown that a peak of the average Nusselt number is observed for a Strouhal number close to 1.

More recently, Selimefendigil and Öztop (2014c) have investigated the flow in a ventilated cavity with two symmetrical inlets and outlet ports, and by considering buoyancy effects. They have considered several variants such as time forcing inlets and a stationary or rotating cylinder inside the cavity (Selimefendigil and Öztop, 2014c, 2015). Nanofluid and ferrofluid have also been investigated (Selimefendigil and Öztop, 2014a,b). From the amount of results, the rise of heat transfer with respect to Reynolds or Grashof numbers should be noted. Moreover, for a prescribed harmonic inlet forcing, a periodic regime is noted (Selimefendigil and Öztop, 2014b). In this case, the lowest Nusselt number is achieved for the highest frequency.

Based on the above literature review, all results involve incompressible flows with the Boussinesq approximation for the buoyancy term. However, this assumption is valid for density nearly constant. Several works based on the low-Mach-number model (Paolucci, 1982) show the importance of the density variation even at low speed flow. For instance, Nicoud (2000) has performed a simulation of the turbulent flow and shown that the mean flow admits an asymmetrical feature due to the mean gradient temperature. The low-Mach-number model has been also retained to predict natural convection flow in a differentially heated cavity with prescribed large temperature gradients (Le Quéré et al., 2005). More recently, Sun and Lauriat (2009) and Sun et al. (2010) have analyzed the heat and mass transfers in a cavity based on the low-Mach assumption. Some discrepancies are noted for the local Nusselt and Sherwood numbers, in comparison with the Boussinesq limit. In addition to mass or thermal Rayleigh numbers, the low-Mach model introduces a parameter denoted $\epsilon$, which refers to the deviation from the Boussinesq assumption, and a thermodynamic pressure for closed enclosures (Sun and Lauriat, 2009).

Regarding the present literature review, it appears that no work is reported for mixed convection in a ventilated enclosure based on the low-Mach-number approach. So here we propose to investigate it. The geometrical configuration of Saeidi and Khodadadi (2007) is retained with one inlet and one outlet port. Moreover, the buoyancy effect and density variations are also considered to compute steady laminar flow. Section 2 describes the geometrical and governing equations. Next, the numerical method for the computation of solutions is detailed. The numerical results, including the code validation, are discussed in Section 4. 


\section{PROBLEM FORMULATION}

\subsection{Flow Configuration}

A sketch of the physical problem is shown in Fig. 1. A square cavity of height $H$ is considered with an inlet and outlet ports located at the left-top and right-bottom walls, respectively. The size of these ports is $h=0.25 H$. The temperature $T_{h}$ at the walls is constant. At the inlet port, a uniform velocity $u_{i}$ and temperature $T_{c}$ are prescribed. It is assumed that the incoming fluid flow temperature is lower than the wall temperature $T_{c}<T_{h}$. The physical properties of the fluid are assumed to be constant and determined at the reference temperature $T_{r e f}=\left(T_{c}+T_{h}\right) / 2$. Depending on the inlet velocity and temperature gradient, the flow could be driven by forced, mixed, or natural convection. The governing equations are described hereafter.

\subsection{Governing Equations}

The flow is assumed to be two-dimensional, and the low-Mach-number model is considered for density variation. This formulation can deal with large temperature differences and/or large mass fraction differences in contrast to the Boussinesq approximation. From a practical point of view, this model is more suitable than the compressible model because acoustic waves are not considered. This relaxes the stability constraints of such numerical solvers (Paolucci, 1982). This model relies on the decomposition of the motion pressure into a fluctuating part $p$ and a thermodynamic pressure $\mathrm{P}_{t h}$. The former satisfies the equation of state (ideal gas law). The dimensionless equations read

$$
\frac{\partial \rho}{\partial t}+\nabla \cdot \rho \mathbf{u}=0
$$

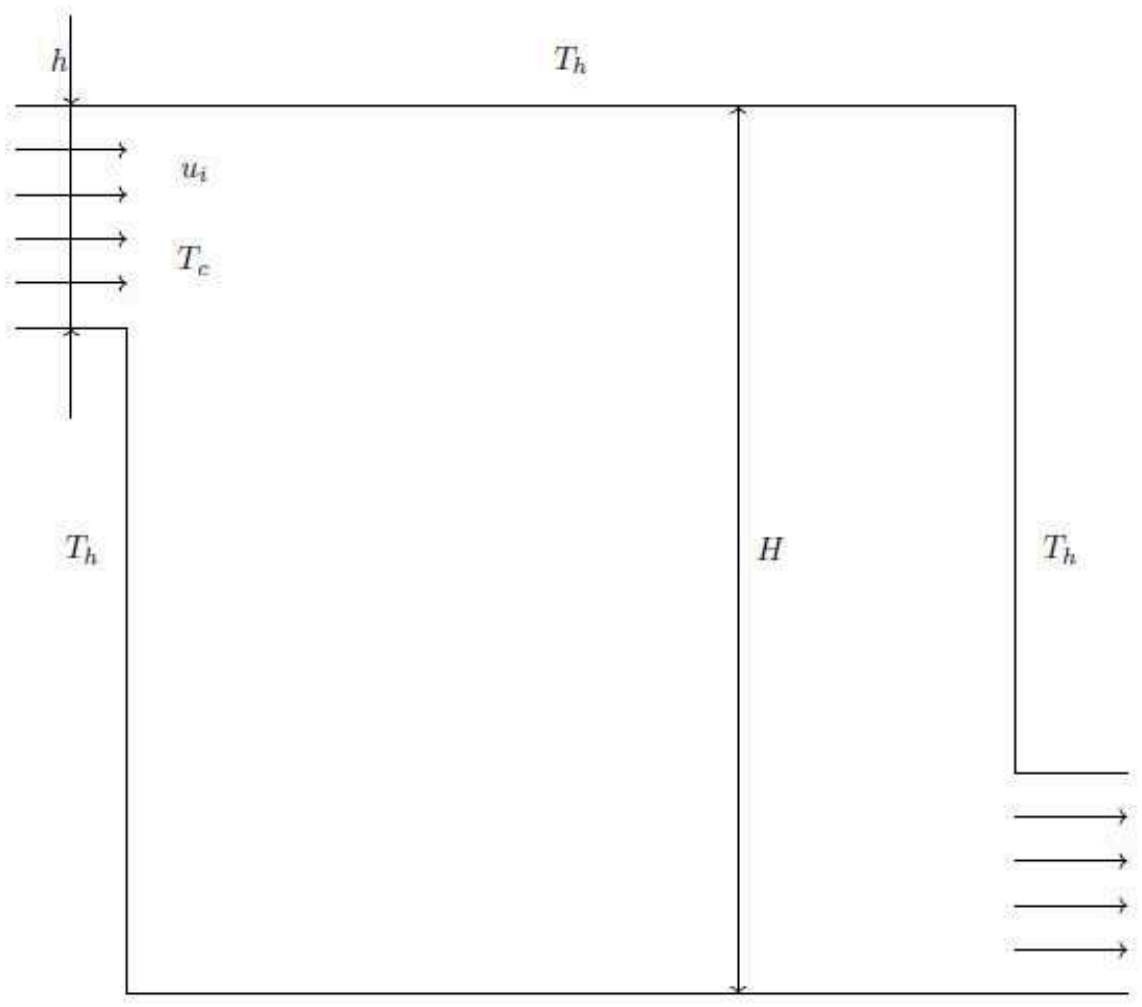

$T_{h}$

FIG. 1: Sketch of the ventilated cavity 


$$
\begin{aligned}
\frac{\partial \rho \mathbf{u}}{\partial t}+\nabla \cdot \rho \mathbf{u} \otimes \mathbf{u} & =-\nabla p+\nabla \overline{\bar{\tau}}+\frac{\mathrm{Ri}}{\epsilon}(\rho-1) \mathbf{g} \\
\rho \frac{\partial \theta}{\partial t}+\nabla \cdot(\rho \mathbf{u} \theta) & =\frac{1}{\operatorname{RePr}} \nabla \cdot(\nabla \theta)+\frac{\gamma-1}{\epsilon \gamma} \mathrm{d}_{t} \mathrm{P}_{t h} \\
\mathrm{P}_{t h} & =\rho(1+\epsilon \theta)
\end{aligned}
$$

where the vector $\mathbf{u}=[u, v]^{t}$ stands for the dimensionless velocity and $p$ for the dimensionless pressure. These dimensionless equations are derived from the reference length and velocity, $H$ and $u_{i}$, respectively. The dimensionless density $\rho$ stands for the ratio between the fluid density and the inlet density $\rho_{i}$. The dimensionless temperature is defined by $\theta=\left(T-T_{c}\right) /\left(T_{h}-T_{c}\right)$. The Reynolds and Grashof numbers are defined by $\operatorname{Re}=u_{i} H / v$ and $\mathrm{Gr}=$ $H^{3} g \epsilon / v^{2}$, respectively. The parameter $\epsilon=1-T_{c} / T_{h}$ is the deviation from the Boussinesq approximation. The boundary conditions are described in Section 2.1, except for the outlet port, for which the homogeneous Neumann boundary conditions are prescribed for each variable.

\section{NUMERICAL METHODS}

\subsection{Method of Solutions}

The numerical solution of the low-Mach-number formulation, Eqs. (1)-(4), is addressed by means of a fractional step method for the incompressible Navier-Stokes equations. It should be noted that an interesting review has been proposed by Knikker (2011). The main idea is to write the constraint on the divergence velocity and to enforce it with a pressure correction equation. The constraint on the divergence velocity is

$$
\nabla \cdot \mathbf{u}=\frac{1}{V} \frac{1}{\mathrm{P}_{t h}}\left(\frac{1}{\operatorname{RePr}} \nabla \cdot \nabla \theta-\frac{1}{\gamma} \mathrm{d}_{t} \mathrm{P}_{t h}\right)
$$

where $V$ is the volume of the enclosure. The volume integration of this constraint leads to a relation for the temporal derivative of the thermodynamic pressure:

$$
\mathrm{d}_{t} \mathrm{P}_{t h}=\frac{1}{V} \frac{1}{\mathrm{P}_{t h}} \frac{1}{\operatorname{RePr}} \int_{V} \nabla \cdot \nabla \theta \mathrm{d} V
$$

In comparison with incompressible Navier-Stokes equations, the two main differences involve the temperature equation and the velocity divergence. First, the temporal derivative of the thermodynamic pressure acts in the temperature equation and the velocity divergence. Then, the diffusive terms of the temperature appear in the velocity divergence. The procedure to solve the low-Mach-number formulation is based on the review of Knikker (2011). The implemented algorithm involves the semi-explicit backward Euler/Adam Bashfort (EB2/AB) time scheme, which is second-order accurate. The main steps are noted as follows:

1. Advance the temperature. The variable $\theta^{n+1}$ is computed from the time-discretized temperature equation. The new thermodynamic pressure is updated from $\mathrm{P}_{t h}=M_{0} / \int 1 / \theta d v$.

2. Advance the density. The density $\rho^{n+1}$ is evaluated from $\rho^{n+1}=\mathrm{P}_{t h} /\left(1+\epsilon \theta^{n+1}\right)$.

3. Compute the provisional velocity. The momentum equations are advanced in time to provide a provisional velocity field which does not fulfill the divergence constraint.

4. Pressure correction step. A pressure correction equation (Poisson) with variable coefficient is solved to enforce the divergence constraint.

5. Velocity correction. In this final step the provisional velocity is corrected by means of the gradient of pressure correction. 
The above procedure is detailed by Knikker (2011) and labeled "projection method with variable-coefficient Poisson equation." The time step is such that the CFL condition is always lower than 1/2. The staggered grid layout is retained and combined with a second-order finite-difference discretization. The mesh can be stretched by means of analytic mesh transformation (Vinokur, 1983). The solutions to the linear systems arising from the discretization of the temperature, the momentum, and the pressure equations are tackled with a geometric multigrid solver. Particularly, the solver provided by the HYPRE library (Falgout et al., 2006) has been used in this work.

\subsection{Validation}

The code validation is made by considering the benchmark of the differentially heated cavity with a large temperature gradient (Bouafia et al., 2015; Knikker, 2011; Sun and Lauriat, 2009). The benchmark case is described by Le Quéré et al. (2005) and consists in computing the natural convection in a two-dimensional square cavity for which the isotherm left and right walls define the temperature gradient $\Delta T=T_{h}-T_{c}$, while the top and bottom walls are adiabatic. The working fluid is an ideal gas; its properties, except density, remain constant. The benchmark case is uniquely defined if the Grashof, Prandtl, and the thermal expansion parameter $\epsilon$ are known. A very fine mesh of size $1024 \times 1024$ refined at the vicinity of the walls is considered to calculate an accurate solution for the set of parameters: $\mathrm{Gr}=10^{6}, \mathrm{Pr}=0.71$, and $\epsilon=0.6 . H$ being the height of the cavity, the smallest and biggest cell sizes are equal to $0.00049 \mathrm{H}$ and $0.00149 \mathrm{H}$, respectively. Such a mesh refinement is achieved by using a tangent hyperbolic mesh transformation (Vinokur, 1983). The isotherms and the streamlines are plotted in Fig. 2. This plot, for instance, can be compared with Fig. 2 of the recent work of Bouafia et al. (2015). Regarding the general features of this flow, the present results are in good agreement with previous works. A more specific comparison with the Nusselt number and the thermodynamic pressure is proposed in the Table 1 . The quantities of interest are the average, minimum, and maximum Nusselt numbers on the hot and cold walls of the cavity. The first and second column provide the present code and Vierendeels' solutions, respectively. It should be pointed out that the data of Vierendeels are extracted from the benchmark work detailed by Paillère et al. (2005). An excellent agreement is noted for all the heat transfer characteristics computed with the present code. It can be concluded that the validation of the present numerical method is satisfactory and thus can be used to evaluate the solutions of the low-Mach-number flow in a ventilated cavity.

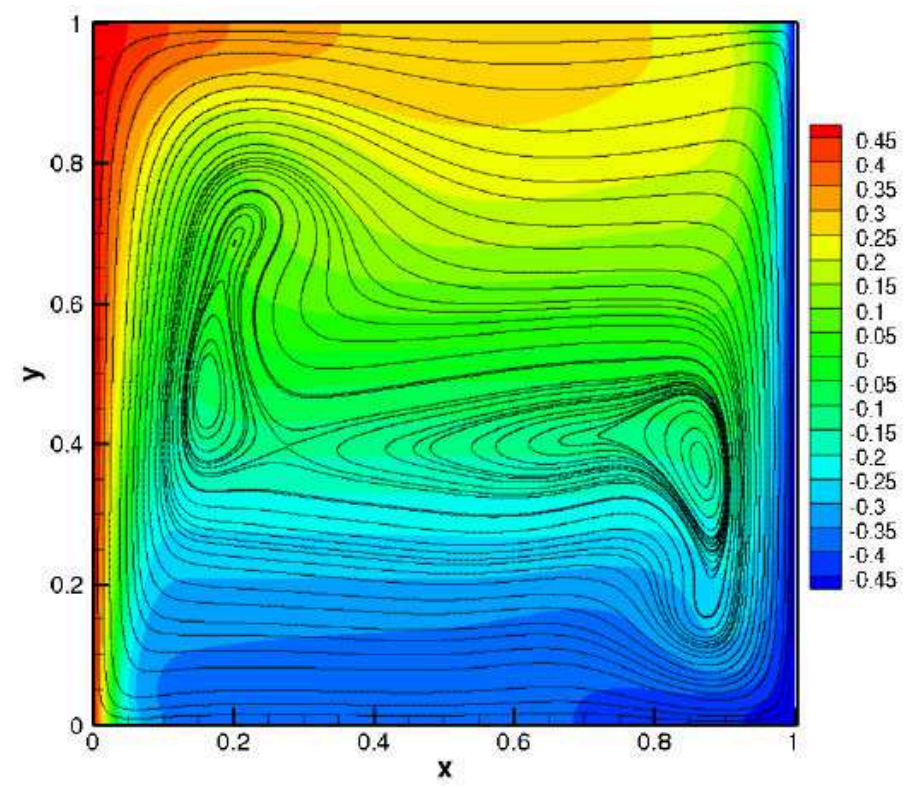

FIG. 2: Isotherms and streamlines of the heated cavity; $\mathrm{Ra}=10^{6}$ and $\epsilon=0.6$ 
TABLE 1: Nusselt number and thermodynamic pressure; $h$ and $c$ refer to the hot and cold wall, respectively

\begin{tabular}{|c|c|c|}
\hline & Present code & Vierendeels \\
\hline Mesh & $1024 \times 1024$ & $2048 \times 2048$ \\
\hline $\mathrm{Nu}_{a v}(h / c)$ & $8.8597 / 8.8601$ & $8.85978 / 8.85978$ \\
\hline $\mathrm{Nu}_{\min }(h / c)$ & $1.0735 / 0.8551$ & $1.0735 / 0.8551$ \\
\hline $\mathrm{Nu}_{\max }(h / c)$ & $19.5984 / 16.3656$ & $19.5964 / 16.3623$ \\
\hline $\mathrm{P}_{t h}$ & 0.856327 & 0.856340 \\
\hline
\end{tabular}

\section{RESULTS}

In this section the flow and heat transfer features are discussed. The simulations of the ventilated cavity flow have been carried out for the following range of dimensionless numbers: $100 \leqslant \operatorname{Re} \leqslant 600,0 \leqslant \mathrm{Gr} \leqslant 10^{5}$, and $10^{-3} \leqslant \epsilon \leqslant$ 0.6 .

\subsection{Numerical Details}

A set of simulations has been carried out to give numerical solutions of the flow for the range of parameters previously mentioned. The criterion to stop the simulation is the residual of each variable: below $10^{-6}$ the solution is assumed converged. The meshes are stretched such as the smallest cells are located at the vicinity of the walls, and the biggest at the center of the cavity. The flow for $\mathrm{Re}=500, \mathrm{Gr}=10^{5}$, and $\epsilon=0.6$ has been computed with four different mesh grid sizes: $40 \times 40,80 \times 80,160 \times 160$, and $320 \times 320$. Then, the velocity and temperature profiles at the middle of the cavity are plotted in Fig. 3.

Figure 3 indicates us that a grid size of $160 \times 160$ is sufficient to accurately describe the flow. In this case, the smallest and the biggest cell sizes are equal to $h_{\min }=0.00315 H$ and $h_{\max }=0.00853 H$, respectively.

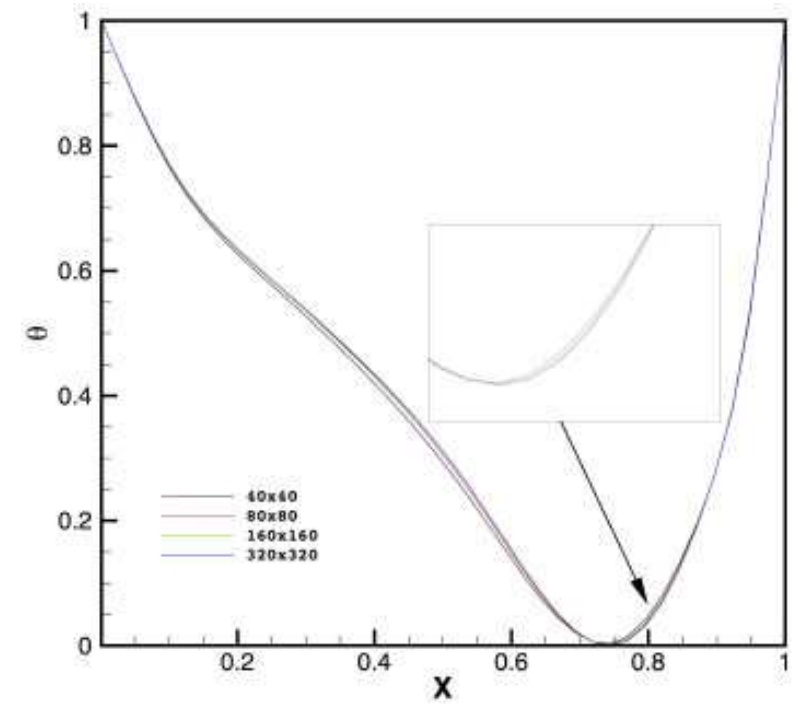

(a)

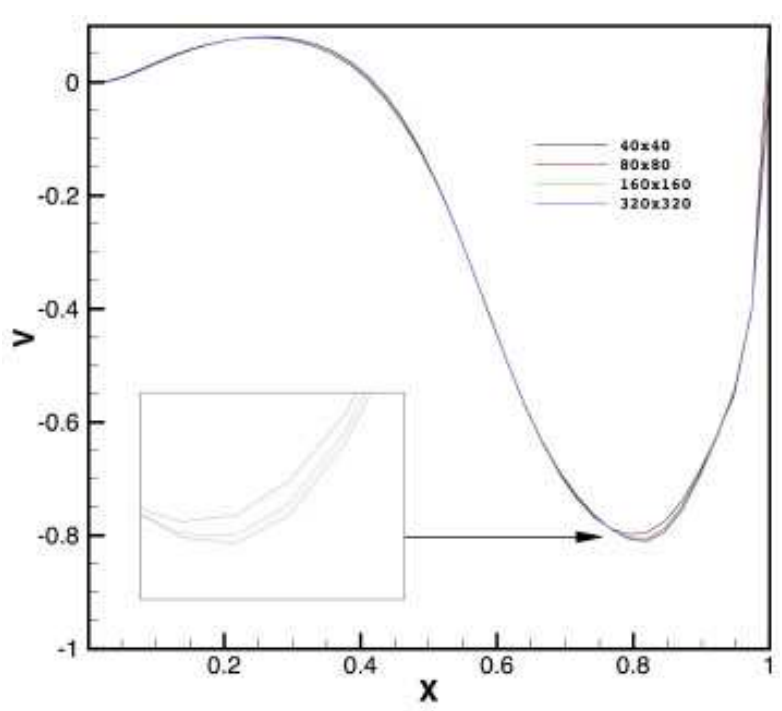

(b)

FIG. 3: Mesh sensitivity analysis; velocity and temperature horizontal profiles at the middle of the cavity; $\operatorname{Re}=500, \mathrm{Gr}=10^{5}$, and $\epsilon=0.6$ 
In the following, the discussions are based on streamlines and iso-temperatures, velocity/temperature profiles, and the Nusselt number. An illustration is given in Fig. 4 for the case $\operatorname{Re}=400, \mathrm{Gr}=10^{3}$, and $\epsilon=0.4$. The local Nusselt number is computed with:

$$
\mathrm{Nu}(s)=\left.\frac{\partial \theta}{\partial \mathbf{n}}\right|_{s}
$$

where $s$ is a curvilinear coordinate as depicted in Fig. 4(d), and $\mathbf{n}$ the normal of the wall. In this study, the average Nusselt number is obtained by integration over the left and the bottom walls.

For this configuration, the main stream flow, formed between two circulation regions, connects the inlet and the outlet ports. The presence of a primary vortex, $70 \%$ of characteristic length $H$, a secondary vortex next to the

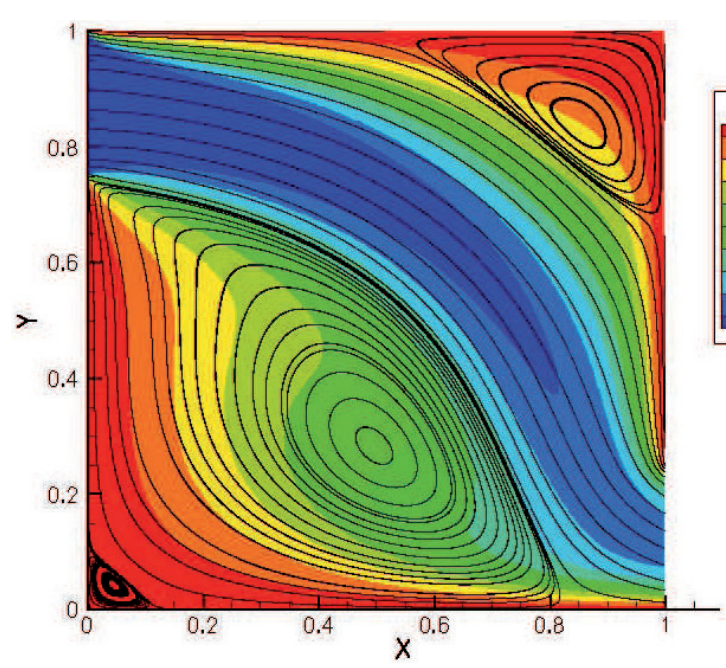

(a)

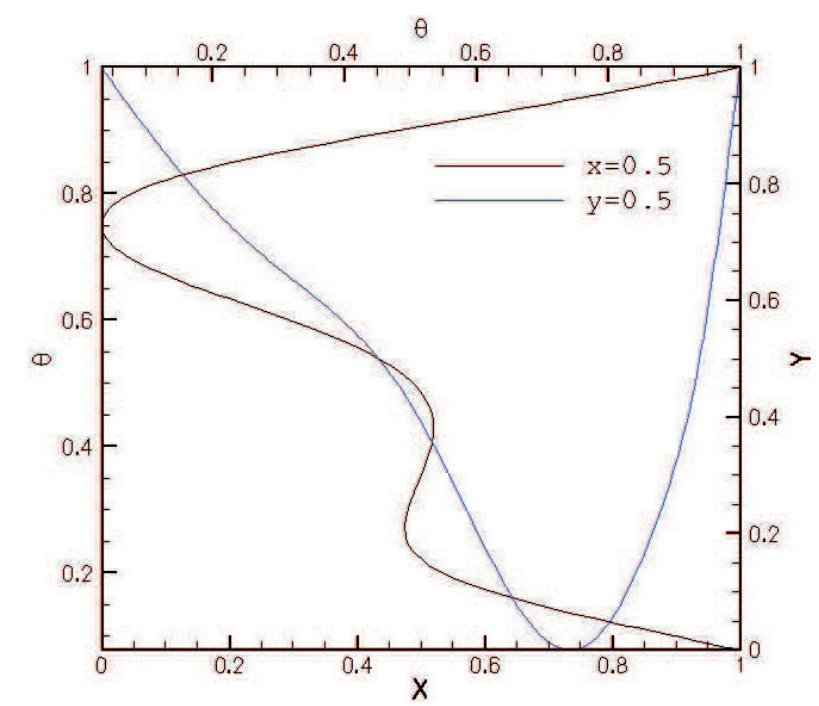

(c)

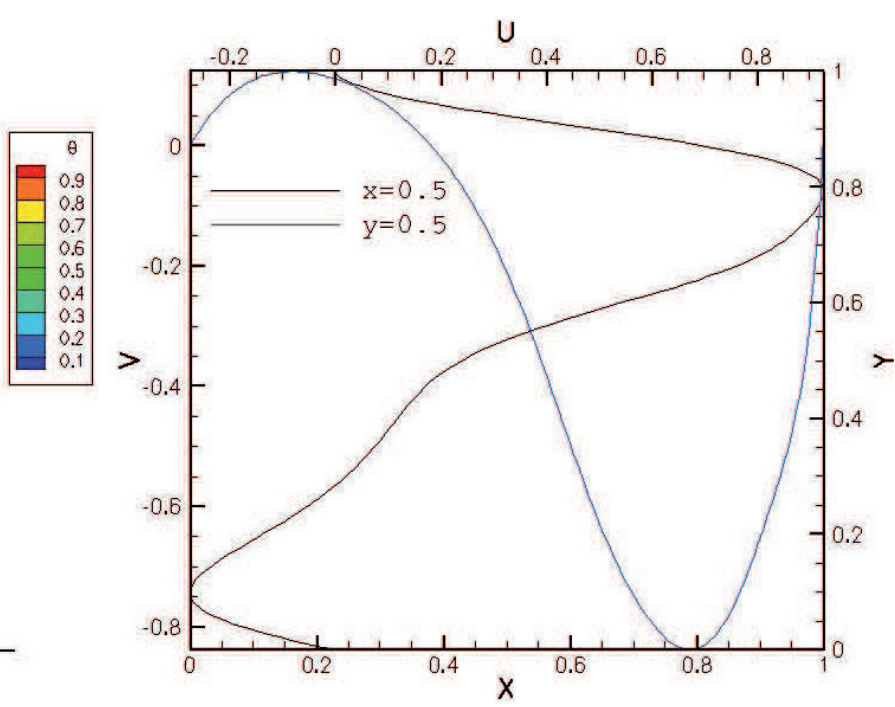

(b)

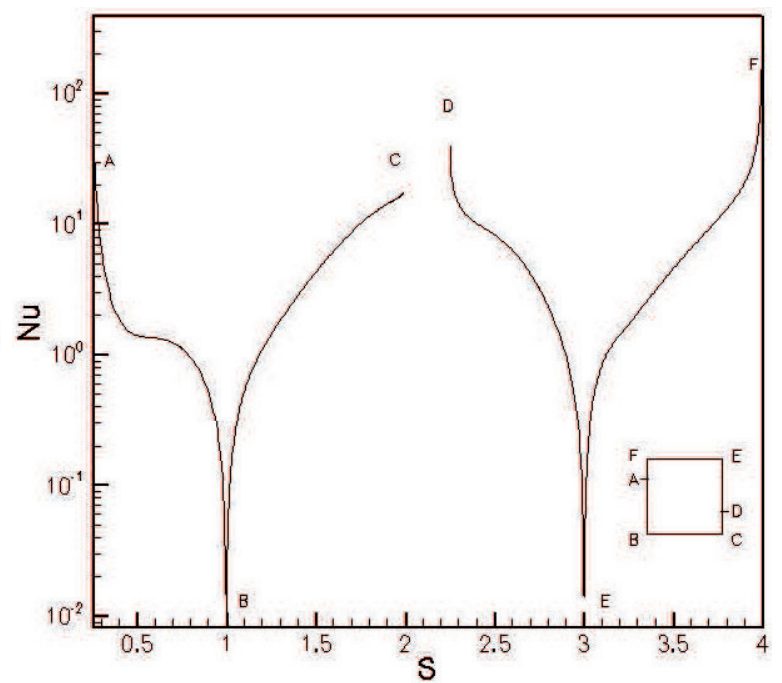

(d)

FIG. 4: Ventilated cavity for the parameters $\mathrm{Re}=400, \mathrm{Gr}=10^{3}, \epsilon=0.4$ : isotherms and streamlines (a), midline velocities (b), midline temperatures (c), and Local Nusselt number profile (d) 
top-right corner part, and a much smaller one at the bottom-left corner is observed. Figure 4(b) shows the profile of the velocities $u$ and $v$ at the vertical and horizontal midlines, respectively. Both velocities have negative sign in the circulation regions and positive sign outside the circulation. The temperature in the two midlines is shown in Fig. 4(c). It is observed that the temperature decreases for $x$ and $y$ values up to 0.5 , which corresponds to the main stream. The local Nusselt number profiles on the four walls of the cavity are plotted in Fig. 4(d). In this figure the curvilinear coordinates $s$ is introduced. It can be noted that the values of the local Nusselt number drop from the maximum values at the openings to minimum values at the bottom-left and top-right corners (the circulation regions).

\subsection{Heat Transfers}

In this section, the heat transfers at the cavity's left and bottom walls are discussed in order to compare the Boussinesq and non-Boussinesq models. Thus the mean Nusselt number is computed from the simulations performed with the Reynolds and Grashof numbers fulfilling the range $100 \leqslant \mathrm{Re} \leqslant 600$ and $0 \leqslant \mathrm{Gr} \leqslant 10^{5}$. As defined previously, the non-Boussinesq parameter is set between $\epsilon=10^{-3}$ and 0.6. Such a choice allows us to consider the forced and the mixed convection regimes, while requiring the Boussinesq $\left(\epsilon=10^{-3}\right)$ and the non-Boussinesq $(\epsilon=0.6)$ models.

The mean Nusselt numbers gathered from the present simulations with the previously defined parameters are represented in Fig. 5.

A specific format is retained in Fig. 5: the mean Nusselt number is plotted with respect to the Richardson number and using a logarithmic scale. Using this data representation, four branches could be clearly revealed. Each branch is associated to a Grashof number, as indicated in Fig. 5. It should be noted that the plot of the branch $\mathrm{Gr}=0$ is made possible by substituting arbitrarily $\mathrm{Gr}=0$ with $\mathrm{Gr}=10^{-2}$. This improves the analysis of the data without modifying the results.

The pure forced convection regime is featured by $\mathrm{Gr}=0$. The mean Nusselt number associated to this regime corresponds to the first branch at the left part of Fig. 5. The lowest and highest mean Nusselt numbers are associated to the Reynolds numbers $\mathrm{Re}=100$ and $\mathrm{Re}=600$, respectively. The thermal expansion parameter $\epsilon$ has no effect on the mean Nusselt number for the lowest Reynolds number $\mathrm{Re}=100$. However, when the Reynolds number increases,

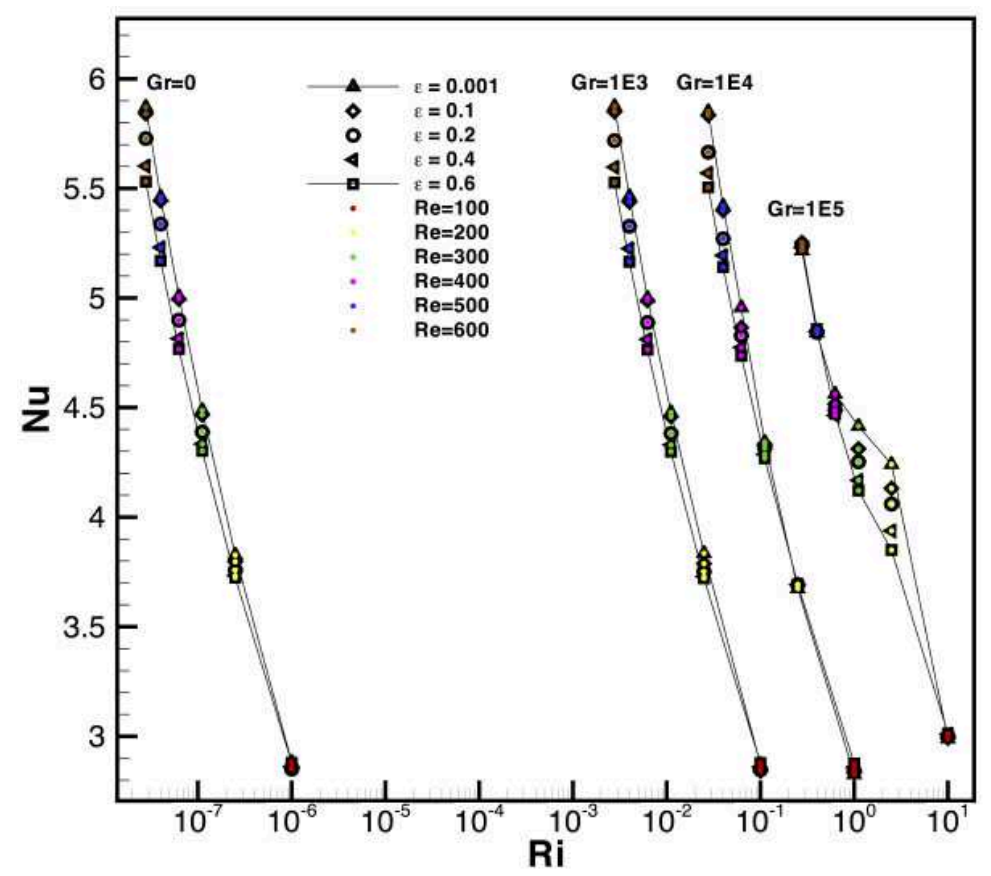

FIG. 5: Mean Nusselt number versus the Richardson number for the different flow parameters $\mathrm{Re}$ and $\mathrm{Gr}$ 
an influence is noted. Thus, for the highest Reynolds number $\mathrm{Re}=600$, the Nusselt numbers spread in the range $5.5 \leq \mathrm{Nu} \leq 6$, while the thermal expansion parameter $\epsilon$ is comprised between $10^{-3}$ and 0.6. Moreover, the discrepancies between the incompressible and quasicompressible flow are quite small. A similar analysis can be achieved with the Grashof numbers $\mathrm{Gr}=10^{3}$ and $\mathrm{Gr}=10^{4}$.

A different behavior is noted for the fourth branch $\mathrm{Gr}=10^{5}$, except for the smallest Reynolds number $\mathrm{Re}=$ 100. For this value, the thermal expansion parameter $\epsilon$ does not influence the mean Nusselt number. A significant influence is observed for the other Reynolds numbers. Moreover, a particular behavior should be noted at $\operatorname{Re}=$ 600 , where, unlike the other branches, the thermal expansion parameter has no significant influence. Irrespective of the density variation model (Boussinesq or non-Boussinesq), the mean Nusselt number is around 5.25. The most important influence of the thermal expansion parameter on the Nusselt number is achieved for the Reynolds numbers comprised between 200 and 400. As can be seen in Fig. 5, the branch stretches into two curves associated to the Boussinesq and the low-Mach approximations. This global analysis of the heat transfers leads us to consider the present data in two groups: the mixed convection regime $\left(\mathrm{Gr}=10^{5}\right)$ and the forced convection regime $(\mathrm{Gr}=0, \mathrm{Gr}=$ $10^{3}, \mathrm{Gr}=10^{4}$ ). In the following section the flow is discussed for the mixed convection regime.

\subsection{The Mixed Convection Regime}

In this section, the mixed convection regime is considered. This corresponds to the simulations carried out with the Grashof number $\mathrm{Gr}=10^{5}$. The present discussion on the influence of the parameter $\epsilon$ focuses on the Reynolds numbers $\operatorname{Re}=100, \operatorname{Re}=600$, and $\operatorname{Re}=200$. The chosen Reynolds numbers correspond to the bottom, top and middle of the fourth branch presented in Fig. 5.

For the Reynolds number $\operatorname{Re}=100$, Fig. 5 exhibits a small influence of the parameter $\epsilon$ on the mean Nusselt number. In this case, the local Nusselt numbers at the left and bottom walls of the cavity are investigated. The local Nusselt number is plotted in Fig. 6(a).

Its values, at the left wall, are smaller for the low-Mach approximation in comparison with the Boussinesq limit. In contrast, at the bottom wall, greater values of the local Nusselt number are observed for the low-Mach regime. This rise could be associated to the buoyancy forces induced by the temperature gradient. The balance of the local Nusselt numbers at the left and the bottom walls of the cavity leads to a small variation of the mean Nusselt number. The isotherms and the streamlines associated to the former parameters are presented in Figs. 7(a) and 7(b). The dominated natural convection can be noted.

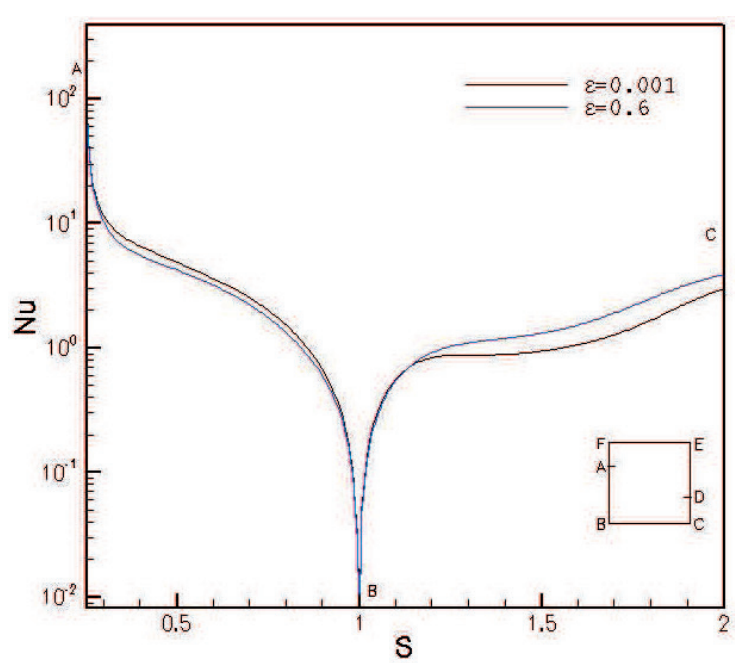

(a)

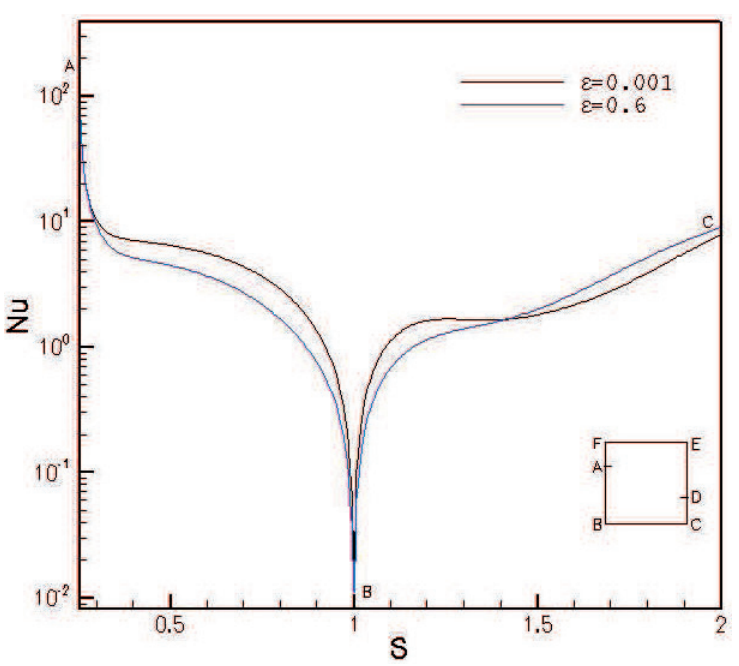

(b)

FIG. 6 


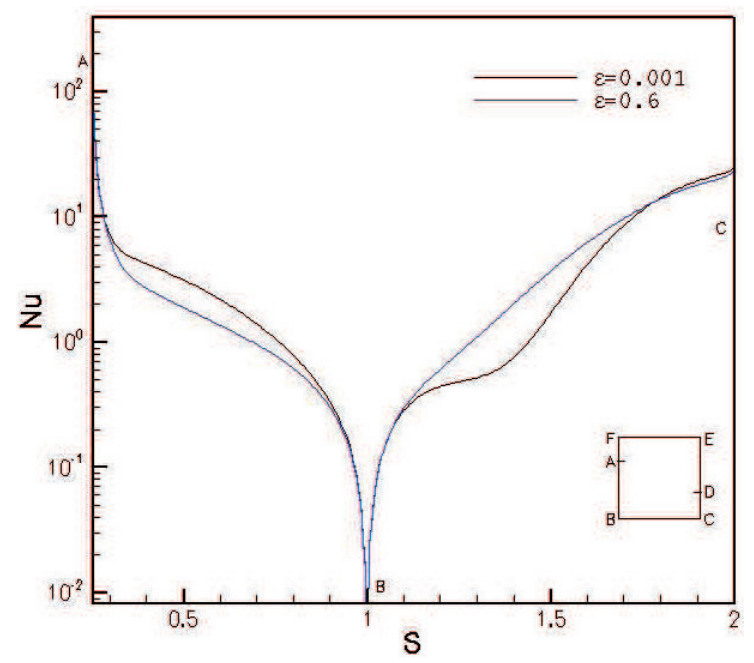

(c)

FIG. 6: Local Nusselt number for the mixed convection regime $\left(\mathrm{Gr}=10^{5}\right): \operatorname{Re}=100$ (a), $\operatorname{Re}=200$ (b), and $\operatorname{Re}=600$ (c)

A recirculation region occurs at the center of the cavity while the main stream, which connects the inlet to the outlet ports, filled the upper and right parts of the cavity. The size of the recirculation structures decreases for the largest values of thermal expansion parameters $\epsilon$ [Fig. 7(b)].

A similar analysis holds for the Reynolds number $\mathrm{Re}=600$. Figure 6(c) shows the local Nusselt number. At the left wall of the cavity, the local Nusselt number values at the low Mach regime are smaller in comparison with the Boussinesq limit, while greater values of the local Nusselt number at the low-Mach regime are observed at the bottom wall. A new flow topology is noted on the left part of the cavity, Figs. 7(e) and 7(f). Two vortices are observed at the left part of the cavity. The presence of these vortices is due to the interaction between the jet flow and buoyancy forces. They represent about $80 \%$ of the cavity height $(H)$. The dimensions of the cells change as the thermal expansion parameter increases, whereas the total height of these two vortices remains constant. Another recirculation zone is observed next to the top-right corner. Concerning the heat transfers at the left and bottom walls, the present results highlight the effect of the recirculation zones on the local Nusselt number. Thus, in the Boussinesq limit the bottom-left circulation is stronger than the non-Boussinesq approximation [Fig. 7(f)]. Indeed, at the left wall of the cavity the local Nusselt heat transfer is higher for the Boussinesq limit. At the bottom wall the opposite phenomena holds. In fact, the cell confined between the jet stream and the lower left circulation has become stronger for the non-Boussinesq approximation. Moreover, its center has moved toward the bottom wall. The shear stress also becomes important at the vicinity of the bottom wall, leading to a rise of the local Nusselt number.

Here, the local Nusselt number for $\mathrm{Re}=200$ is considered. According to Fig. 5, an influence of the thermal expansion parameter is noted. To explain this, the local Nusselt numbers at the left and the bottom walls are considered [Fig. 6(b)]. The discrepancies between the Boussinesq limit $\left(\epsilon=10^{-3}\right)$ and the non-Boussinesq approximation $(\epsilon=0.6)$ originate from the left wall. In the first-half part of the bottom wall, the Nusselt number in the Boussinesq limit is higher than the one computed with the non-Boussinesq approximation. In the second-half part of the bottom wall, the opposite behavior is observed. Thus the average Nusselt number at the bottom wall is quite similar for the two models. The discrepancies originate from the left wall, as noted in Fig. 6(b), on which the Nusselt number in the Boussinesq limit is notably higher than the non-Boussinesq approximation. In the case of the non-Boussinesq model $(\epsilon=0.6)$ the secondary recirculation region, which occurs at the left wall below the flow inlet, is 3 times bigger [Figs. 7(c) and 7(d)] than the one noted in the Boussinesq limit $(\epsilon=0.001)$. The growth of this secondary recirculation has for a consequence that the wall shear stress decreases and, in a similar way, the heat transfers. The tightened isotherms in the Boussinesq limit [Fig. 7(c)], which are no longer observed in the non-Boussinesq approximation, corroborate this analysis. 


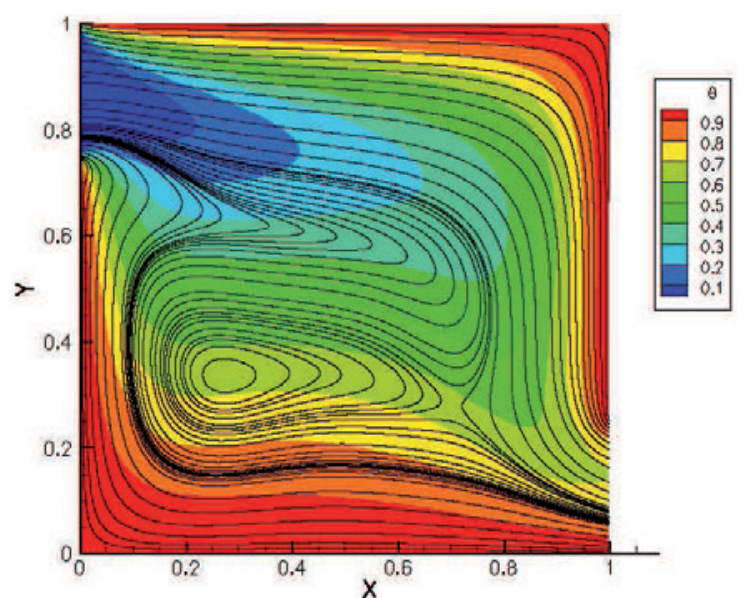

(a)

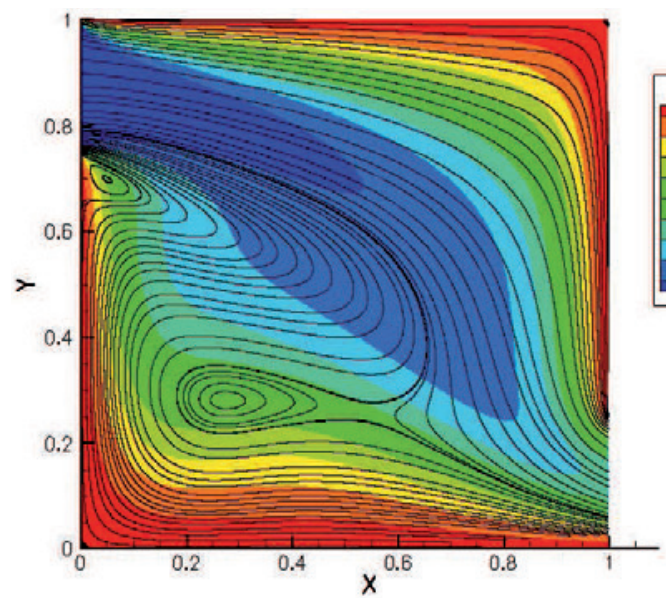

(c)

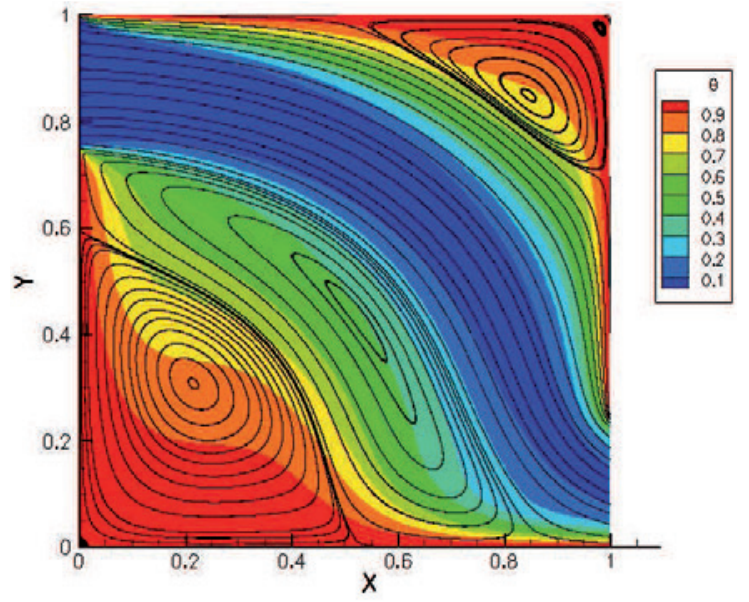

(e)

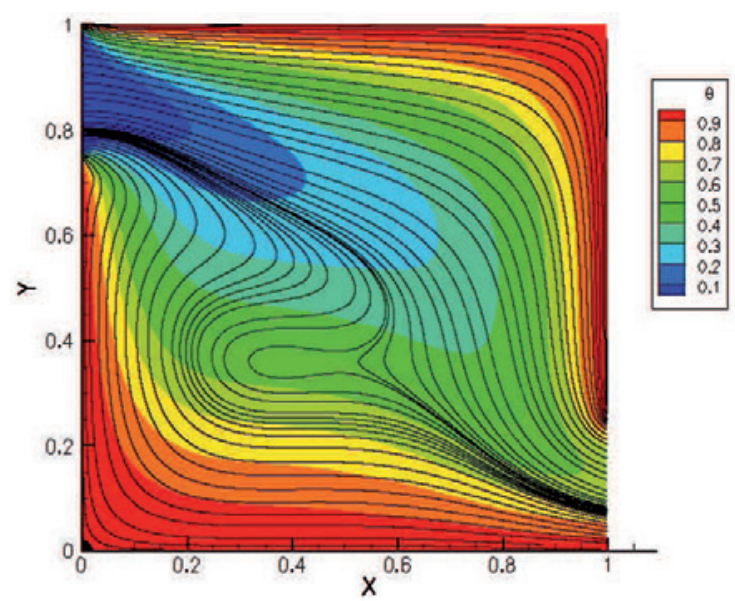

(b)

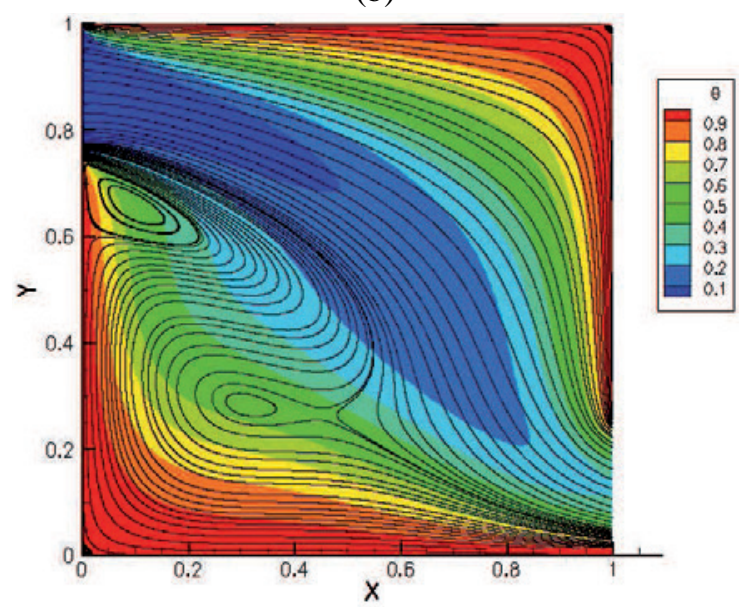

(d)

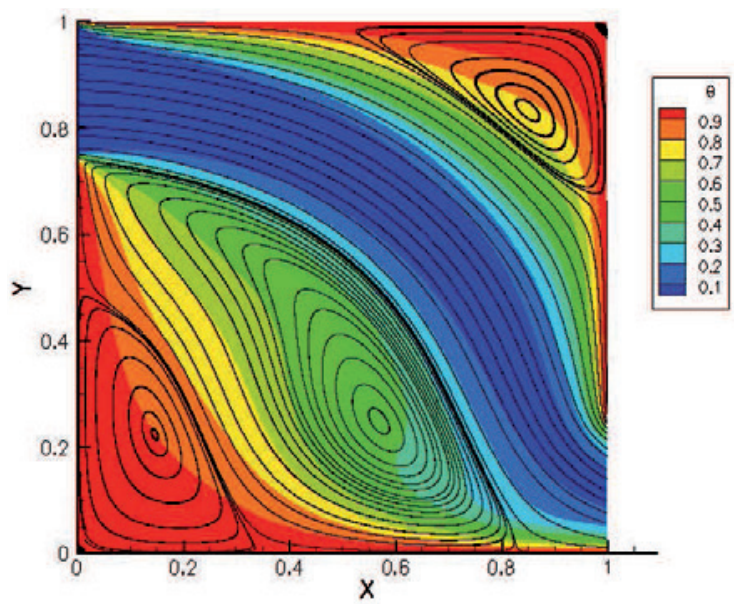

(f)

FIG. 7: Isotherms and streamlines for the mixed convection regime $\left(\mathrm{Gr}=10^{5}\right)$ : $\operatorname{Re}=100(\mathrm{a}, \mathrm{b}), \operatorname{Re}=200(\mathrm{c}, \mathrm{d}), \operatorname{Re}=600(\mathrm{e}, \mathrm{f})$; left column $\epsilon=0.001$ and right column $\epsilon=0.6$ 


\subsection{The Forced Convection Regime}

This section is devoted to the description of the forced convection regime. This corresponds to the Grashof numbers $\mathrm{Gr}=0, \mathrm{Gr}=10^{3}$, and $\mathrm{Gr}=10^{4}$, and the Reynolds numbers such as the Richardson number is lower than 1. Moreover, the behavior of the flow and the heat transfers is quite similar for the three Grashof numbers at the lower Reynolds numbers. A slight dependency with respect to the thermal expansion parameter is noted for increasing Reynolds number (Fig. 5). So, in the following, the discussion focuses on the Grashof number Gr $=10^{3}$ and for the Reynolds numbers $\operatorname{Re}=100, \operatorname{Re}=200$, and $\operatorname{Re}=600$. First, for the Reynolds number $\operatorname{Re}=100$ there is no noticeable dependency with respect to the thermal expansion parameter $\epsilon$. The local Nusselt number at the left and the bottom walls is plotted in Fig. 8(a).

The local Nusselt number is very similar, whatever the thermal expansion parameter $\epsilon$. The flow consists of a main stream connecting the inlet and the outlet ports, a main circulation at the bottom left of the cavity, and a small one at the upper right [Fig. 9(a)]. The Boussinesq and non-Boussinesq flows are very similar [Figs. 9(a) and 9(b)].

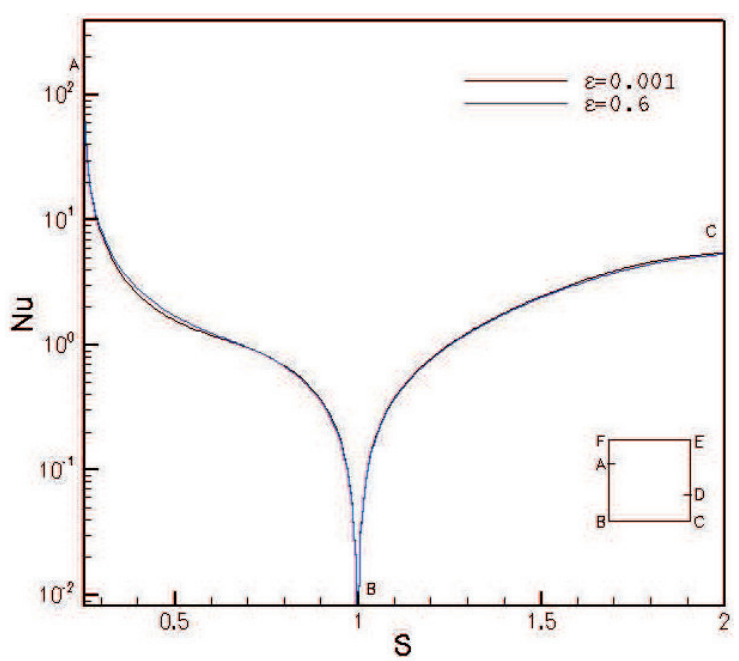

(a)

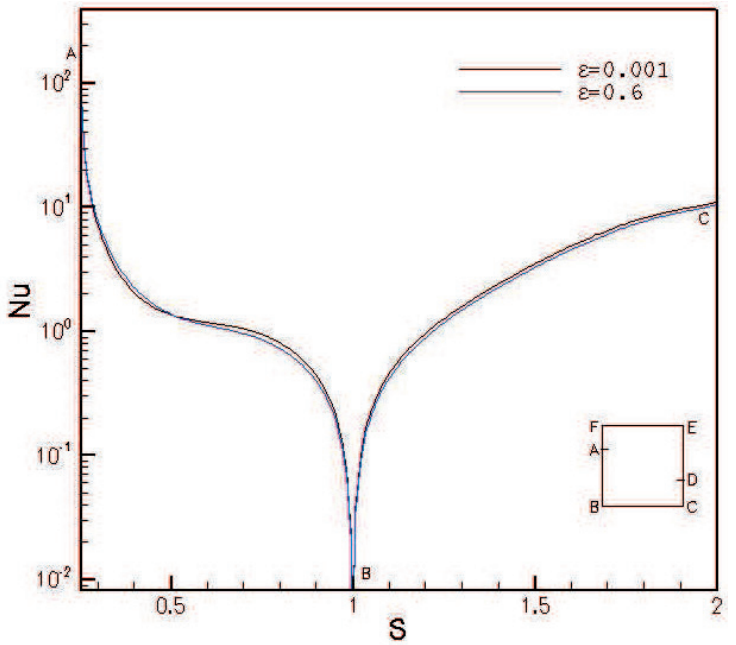

(b)

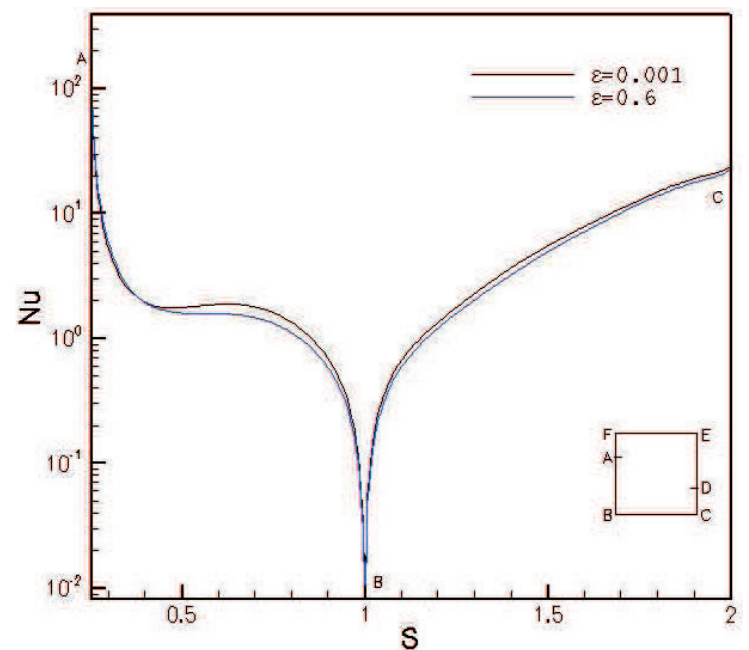

(c)

FIG. 8: Local Nusselt number for the forced convection regime $\left(\mathrm{Gr}=10^{3}\right): \operatorname{Re}=100(\mathrm{a}), \operatorname{Re}=200$ (b), and $\operatorname{Re}=600$ (c) 


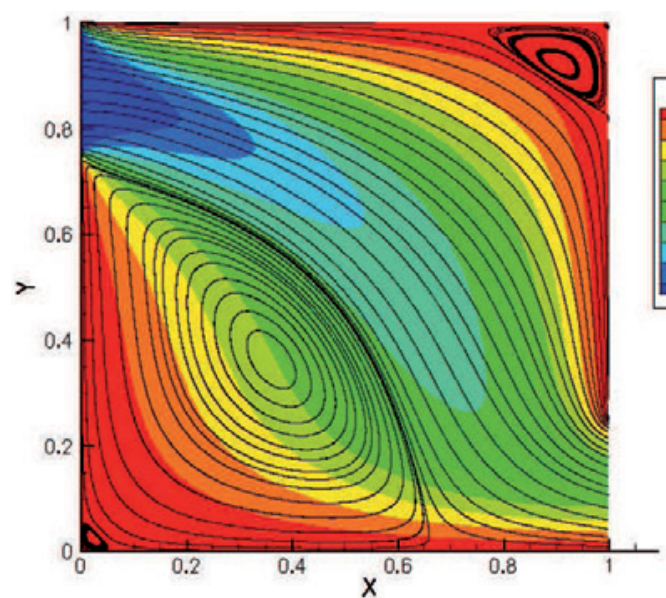

(a)

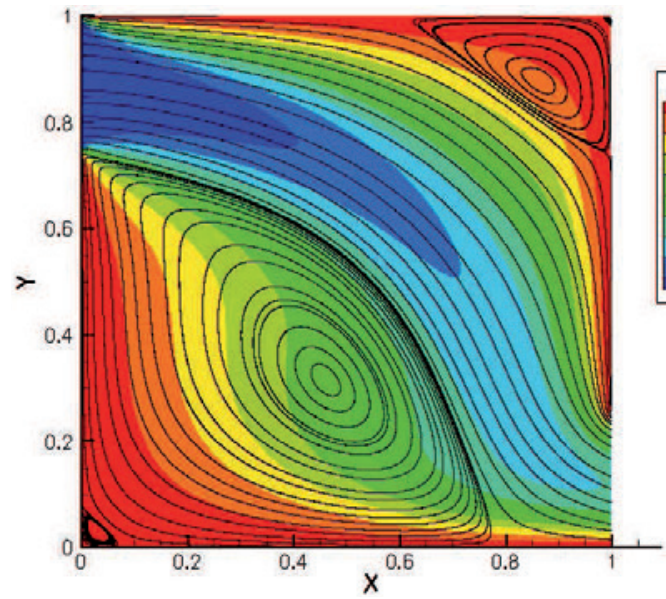

(c)

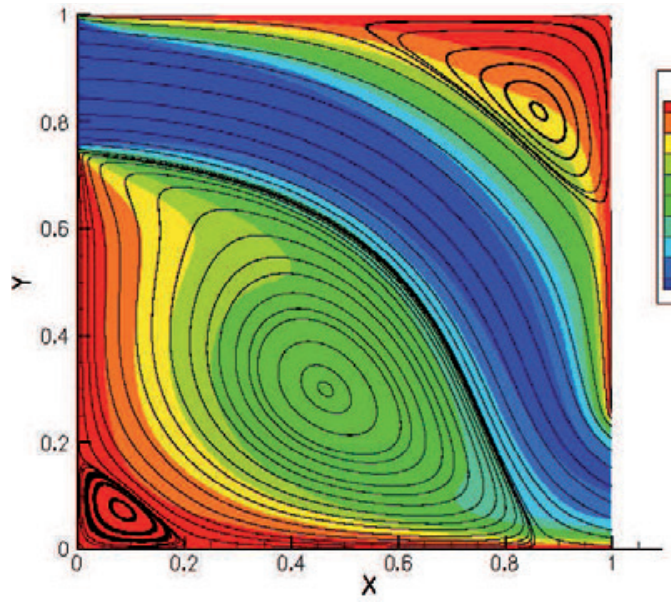

(e)

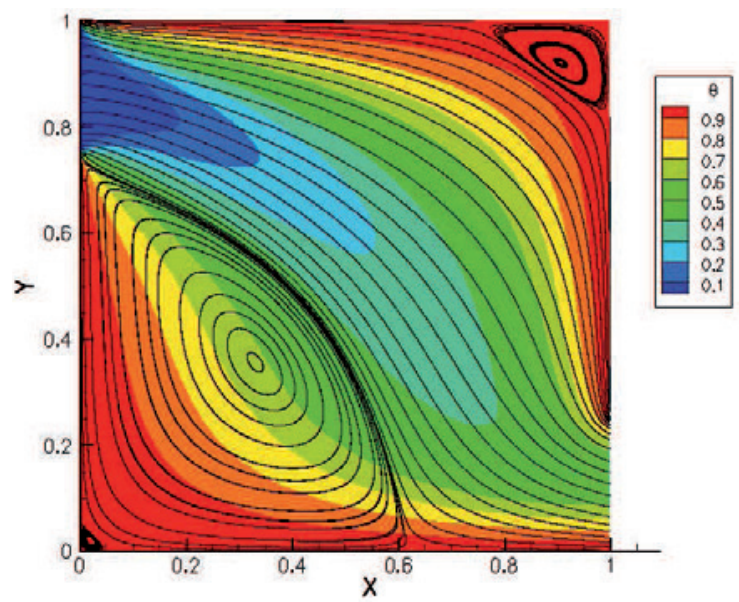

(b)

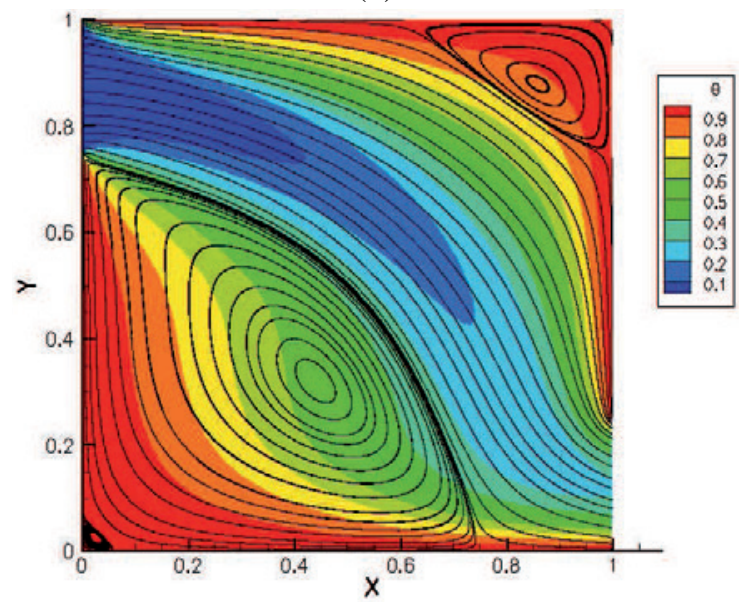

(d)

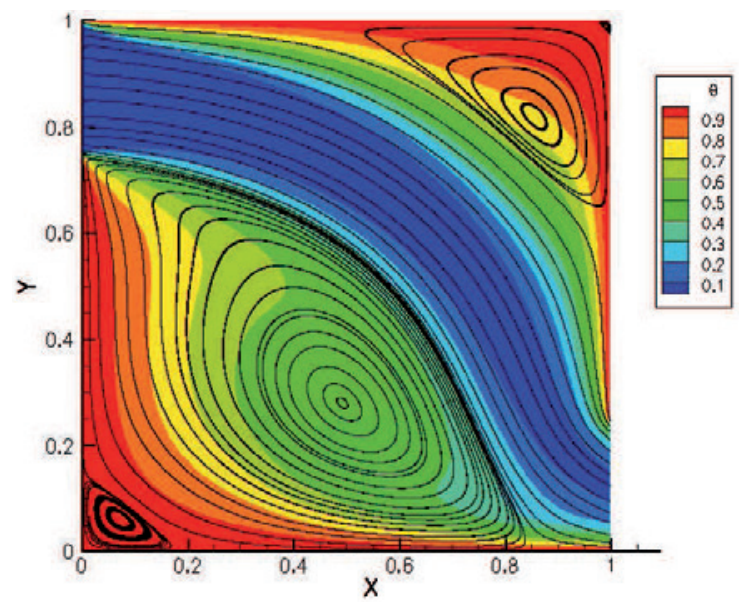

(f)

FIG. 9: Isotherms and streamlines for the forced convection regime $\left(\mathrm{Gr}=10^{3}\right)$ : $\operatorname{Re}=100(\mathrm{a}, \mathrm{b}), \operatorname{Re}=200(\mathrm{c}, \mathrm{d}), \operatorname{Re}=600(\mathrm{e}, \mathrm{f})$; left column $\epsilon=0.001$ and right column $\epsilon=0.6$ 
A similar conclusion can be drawn for the Reynolds number $\mathrm{Re}=200$; there is no significant effect of the density variation modeling. In comparison with the Reynolds number $\mathrm{Re}=100$, the main recirculation at the bottom left is bigger and the isotherms are more stiff at the left wall [Figs. 9(c) and 9(d)].

The more significant discrepancies occur for the Reynolds number $\mathrm{Re}=600$. In this case, the mean Nusselt number is higher by using the Boussinesq model than the non-Boussinesq one. A Nusselt number $\mathrm{Nu}=5.9$ versus $\mathrm{Nu}=5.5$ for the non-Boussinesq approach is noted. The flow is also slightly modified. The main difference with the two other Reynolds numbers is that a small recirculation occurs at the vicinity of the bottom-left corner [Fig. 9(e)]. Moreover, at the left wall the isocontours of temperature are more tightened, which corroborates that the highest Nusselt number is obtained for this Reynolds number. The discrepancies between Boussinesq and non-Boussinesq come from the heat transfer at the left wall, for which the Boussinesq approach provides always a superior local Nusselt number [Fig. 8(c)].

The average Nusselt number on the left and bottom walls and for the Reynolds number $\mathrm{Re}=600$ are summarized in Table 2. This table clearly shows that there is a small influence of the density variation modeling up to Grashof number $\mathrm{Gr}=10^{4}$. For the three Grashof numbers, the mean Nusselt number is around $6 \%$ more by considering the Boussinesq model. For the highest Grashof number $\mathrm{Gr}=10^{5}$ there is no longer a noticeable discrepancy. The difference is about $0.4 \%$.

TABLE 2: Mean Nusselt number on the left and bottom walls of the cavity $(\mathrm{Re}=600)$

\begin{tabular}{ccccc}
\hline $\mathbf{G r}$ & $\mathbf{0}$ & $\mathbf{1 0}^{3}$ & $\mathbf{1 0}^{4}$ & $\mathbf{1 0}^{5}$ \\
\hline$\epsilon=10^{-3}$ & 5.87 & 5.87 & 5.85 & 5.21 \\
\hline$\epsilon=0.6$ & 5.53 & 5.52 & 5.50 & 5.23 \\
\hline
\end{tabular}

\section{CONCLUSION}

A numerical study of a ventilated cavity flow has been presented. The low-Mach-number formulation has been retained to include buoyancy effects without the Boussinesq assumption. The governing equations have been discretized by means of second-order finite-difference discretization. A projection scheme to deal with the velocity/pressure and thermodynamic pressure coupling has been also considered. The method of solution has been successfully validated by comparisons with the two-dimensional low-Mach-number differentialy heated cavity. Based on this solver, simulations of the steady and two-dimensional flow in a ventilated cavity have been carried out. The range of parameters $100 \leq \operatorname{Re} \leq 600,0 \leq \mathrm{Gr} \leq 10^{5}$, and $0 \leq \epsilon \leq 0.6$ leads to forced and a mixed convection regimes. It has been mainly shown that the thermal expansion parameter has a significant effect on mixed convection flow $\left(\mathrm{Gr}=10^{5}\right.$ and $200 \leq$ $\operatorname{Re} \leq 400$ ). This study could benefit from including the thermal dependency of the fluid properties, and thus to assess their influence on the heat transfers. Also, such a study could be extended to the moist air convection in order to compare the Boussinesq and non-Boussinesq model when heat and mass transfer are combined.

\section{REFERENCES}

Bouafia, M., Hamimid, S., and Guellal, M., Non-Boussinesq convection in a square cavity with surface thermal radiation, Int. J. Therm. Sci., vol. 96, pp. 236-247, 2015.

Ezzouhri, R., Joubert, P., Penot, F., and Mergui, S., Large eddy simulation of turbulent mixed convection in a 3D ventilated cavity: Comparison with existing data, Int. J. Therm. Sci., vol. 48, no. 11, pp. 2017-2024, 2009.

Falgout, R.D., Jones, J.E., and Yang, U.M., The design and implementation of HYPRE, a library of parallel high performance preconditioners, Numerical Solution of Partial Differential Equations on Parallel Computers, New York: Springer, pp. 267294, 2006.

Knikker, R., A comparative study of high-order variable-property segregated algorithms for unsteady low Mach number flows, Int. J. Numer. Methods Fluids, vol. 66, no. 4, pp. 403-427, 2011. 
Le Quéré, P., Weisman, C., Paillère, H., Vierendeels, J., Dick, E., Becker, R., Braack, M., and Locke, J.C.W., Modelling of natural convection flows with large temperature differences: A benchmark problem for low mach number solvers, Part 1 . Reference solutions, ESAIM: Math. Modelling and Numerical Analysis, vol. 39, no. 3, pp. 609-616, 2005.

Limane, A., Fellouah, H., and Galanis, N., Thermo-ventilation study by openfoam of the airflow in a cavity with heated floor, Build. Simul., vol. 8, no. 3, pp. 271-283, 2015.

Nicoud, F., Conservative high-order finite-difference schemes for low-Mach number flows, J. Comput. Phys., vol. 158, no. 1, pp. 71-97, 2000.

Nielsen, P.V., Restivo, A., and Whitelaw, J., The velocity characteristics of ventilated rooms, J. Fluids Eng., vol. 100, no. 3, pp. 291-298, 1978.

Paillère, H., Le Quéré, P., Weisman, C., Vierendeels, J., Dick, E., Braack, M., Dabbene, F., Beccantini, A., Studer, E., Kloczko, T., Corre, C., Heuveline, V., Darbandi, M., and Hosseinizadeh, S., Modelling of natural convection flows with large temperature differences: A benchmark problem for low Mach number solvers, Part 2. Contributions to the June 2004 conference, ESAIM: Math. Model. Numer. Anal., vol. 39, no. 3, pp. 617-621, 2005.

Paolucci, S., Filtering of sound from the Navier-Stokes equations, NASA STI/Recon Technical Report N, vol. 83, 1982.

Saeidi, S. and Khodadadi, J., Forced convection in a square cavity with inlet and outlet ports, Int. J. Heat Mass Transfer, vol. 49, no. 11-12, pp. 1896-1906, 2006.

Saeidi, S. and Khodadadi, J., Transient flow and heat transfer leading to periodic state in a cavity with inlet and outlet ports due to incoming flow oscillation, Int. J. Heat Mass Transfer, vol. 50, no. 3-4, pp. 530-538, 2007.

Selimefendigil, F. and Öztop, H., Estimation of the mixed convection heat transfer of a rotating cylinder in a vented cavity subjected to nanofluid by using generalized neural networks, Numer. Heat Transfer, Part A, vol. 65, no. 2, pp. 165-185, 2014a.

Selimefendigil, F. and Öztop, H., Forced convection of ferrofluids in a vented cavity with a rotating cylinder, Int. J. Therm. Sci., vol. 86, pp. 258-275, 2014b.

Selimefendigil, F. and Öztop, H., Numerical investigation and dynamical analysis of mixed convection in a vented cavity with pulsating flow, Comput. Fluids, vol. 91, pp. 57-67, 2014c.

Selimefendigil, F. and Öztop, H., Effects of phase shift on the heat transfer characteristics in pulsating mixed convection flow in a multiple vented cavity, Appl. Math. Model., vol. 39, no. 13, pp. 3666-3677, 2015.

Sun, H. and Lauriat, G., On the heat and mass transfer analogy for natural convection of non-dilute binary mixtures of ideal gases in cavities, C. R. Méc., vol. 337, no. 3, pp. 141-149, 2009.

Sun, H., Lauriat, G., Sun, D., and Tao, W., Transient double-diffusive convection in an enclosure with large density variations, Int. J. Heat Mass Transfer, vol. 53, no. 4, pp. 615-625, 2010.

van Hooff, T., Blocken, B., Gousseau, P., and van Heijst, G., Counter-gradient diffusion in a slot-ventilated enclosure assessed by LES and RANS, Comput. Fluids, vol. 96, pp. 63-75, 2014.

Vinokur, M., On one-dimensional stretching functions for finite-difference calculations, J. Comput. Phys., vol. 50, no. 2, pp. 215234, 1983.

Zhang, W. and Chen, Q., Large eddy simulation of indoor airflow with a filtered dynamic subgrid scale model, Int. J. Heat Mass Transfer, vol. 43, no. 17, pp. 3219-3231, 2000. 